\title{
Usability Techniques Possible to Use in Diagnostic Tools Interface Improvement
}

\author{
Ryszard Bielski ${ }^{1, *}$, Karol Kufel ${ }^{1}$, Marcin Bielski ${ }^{2}$, Hendra Jantanata ${ }^{3}$, Cezary Graul ${ }^{4}$ \\ ${ }^{1}$ Gdańsk University of Technology, Faculty of Management and Economics, Poland \\ ${ }^{2}$ Shiprepair Yard Nauta SA, Newbuildings Division Gdańsk, Poland \\ ${ }^{3}$ LGT Indonesia, Batam, Riau Island, Indonesia \\ ${ }^{4}$ UTP University of Science and Technology in Bydgoszcz, Faculty of Management, Poland
}

\begin{abstract}
The development of diagnostic tools has caused a rapid increase in the amount of information generated and presented, necessitating the use of computer displays as an interface to data presentation and the use of modern diagnostic tools. The paper presents methods for testing usability that can be used in designing and improving the quality of interfaces of modern diagnostic tools that use communication through graphical user interfaces.
\end{abstract}

\section{BACKGROUND}

Currently, industrial devices are becoming more and more complex, require more and more complex procedures and at the same time expected to be more and more reliable in their operation.

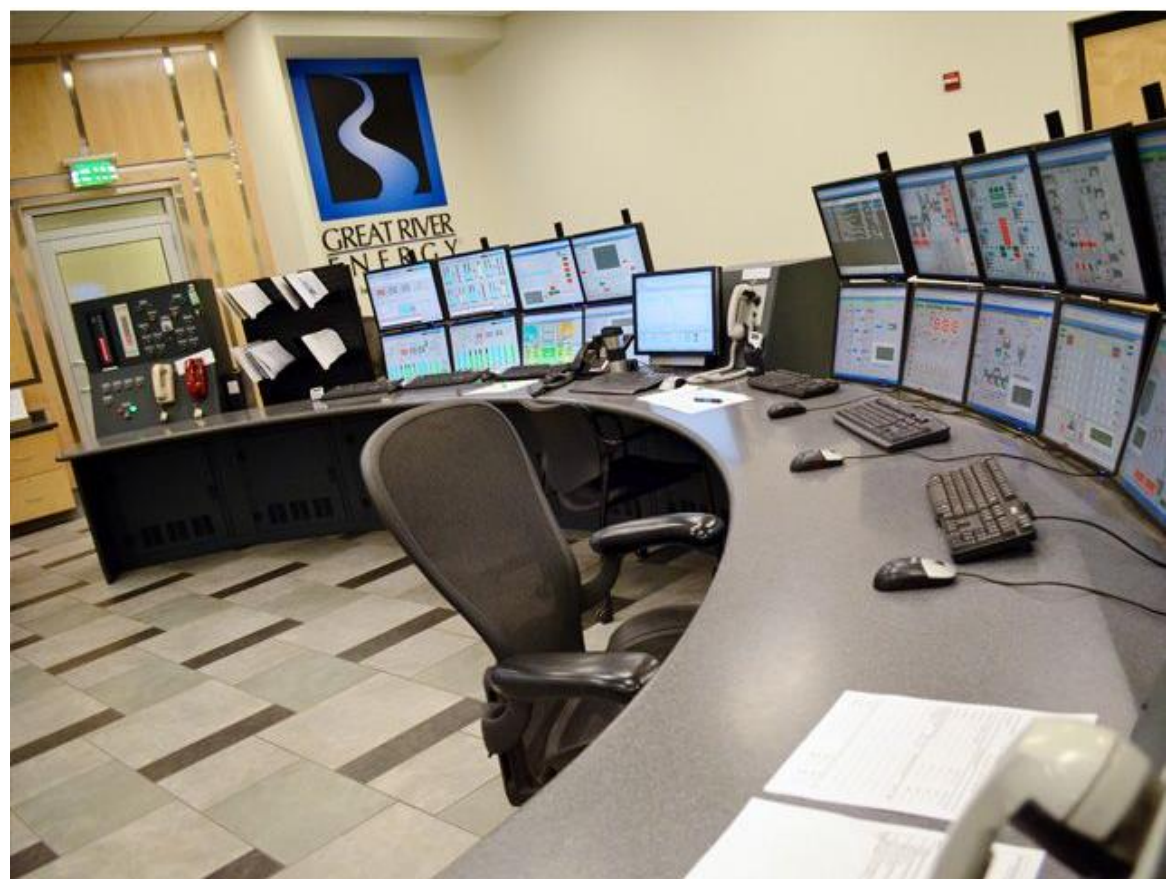

Fig. 1. Power Plant Control Room view.

A natural consequence of meeting the requirements of reliability is the installation of an increasing number of sensors, which, however, generate significant amounts of

*Corresponding author: rysbiels@pg.edu.pl 
measurement data. Their acquisition, processing and interpretation would not be possible without the use of modern technologies, especially computers. Examples of control panels of a nuclear power plant and a modern passenger plane are presented in Fig. 1 and Fig. 2.

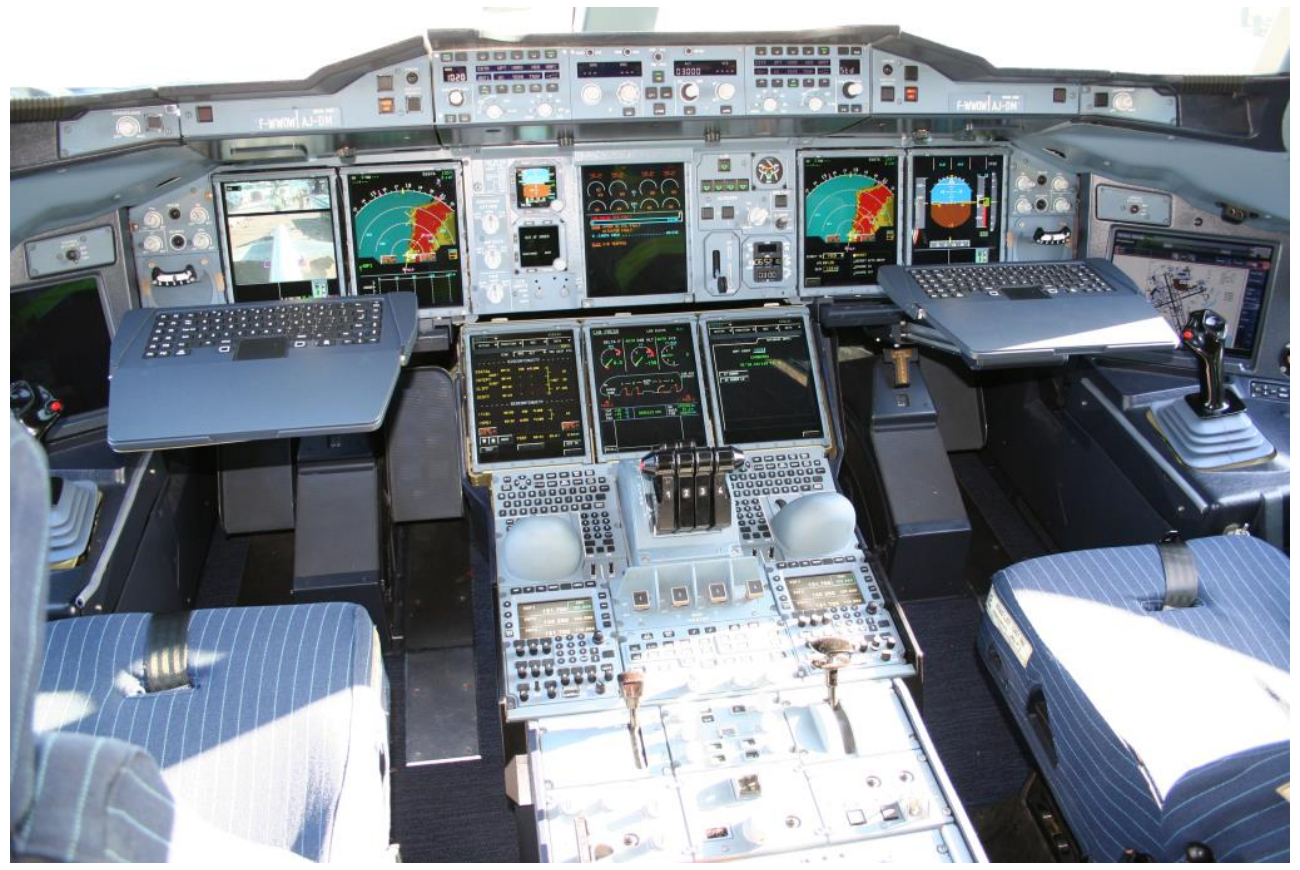

Fig. 2. Airbus A 380 Cockpit view.

At the same time, the amount of diagnostic data generated compels us to deliberate their presentation on computer screens. That is why the quality of the presentation of diagnostic devices on displays is such a critical factor. Their similarity to the screens of computer applications allows the adaptation of techniques known from usability in computers for the analysis, evaluation and evaluation of the quality of diagnostic device interfaces.

\section{USABILITY TECHNIQUES POSSIBLE TO USE IN DIAGNOSTIC TOOLS INTERFACE IMPROVEMENT}

Techniques and usability testing (Usability) are used for testing the usable quality of web services and applications. Many of their methods have been developed. Their knowledge allows to improve IT products and interfaces, identify problems and create recommendations for design. Some research show, that there are elements that may disturb in comfortable use of graphical interfaces. They may be for instance too many moving elements, overspecification or wrong, not expected, misleading answers form automated system $[6,17,24]$. This may be overcame by using guides in development phase, especially in case of older users, who need simplified interfaces [16, 23]. Also emotion-centered techniques, like Kansei engineering may be helpful in delivering high quality, intuitive solutions [7]. Such approach is necessary in research on barriers in the use of all digital products, including diagnostic tools. This publication relays on report [14] and is a review of techniques in this area. Main techniques are shortly presented in following points.

\subsection{Analysis of the context of use (Context of use analysis)}

Analysis of the context of use is a method of obtaining information about the product and its use. During the session with the participation of key persons of the group is being created description of the product itself, information about users, tasks performed by users 
and the environment in which it is performed is obtained. Sessions should be performed as soon as possible, usually during the product planning phase [8]. However, the results of this analysis can be helpful as a reference point also in later stages of product preparation and creation, especially if they are updated on a regular basis in the meantime.

\subsection{Task analysis}

Task analysis determines what the user should do (in the sense of actions or processes) to achieve the assumed goal. A careful analysis of tasks can help to understand the system and the flow of information inside. Analysis of tasks allows for proper development and allocation of tasks within the system, which allows for proper assignment of functionalities in later stages. This is important for correct construction and subsequent system integrity. In particular, it may be a threat that insufficiently accurate diagnosis of tasks performed in the tested system usually increases the risk of expensive problems (resulting from lack of knowledge about the tasks necessary to perform) in the later stages of the project [12].

\subsection{Focus groups}

A focus group is a meeting of all parties with interests (stakeholders) in a given process. Views on the essential elements are cited by the parties. Meetings can be recorded for later analysis. This method is useful at an early stage of product specification or as a way of obtaining comments after a certain period of use. It allows to obtain a multilateral perspective in terms of requirements and identification of elements to which attention should be paid [13].

\subsection{Observation}

Observation methods require the researcher to see users while they are working. During the process, the researcher makes notes on activities that can be observed. The observation may be direct (physically next to the observed person, which may affect the behavior of the observed person) or indirect (using technical means - which is more neutral), including by means of video recording for later analysis [20].

\subsection{Request for context (Contextual inquiry)}

The Contextual inquiry is one of the best methods if you only need to understand the environment in which users perform tasks. Basically, it is a structured interview method, based on a few basic principles that distinguish it from reporter interviews [8]. It is the opposite of the evaluation process and seeks to discover. It is usually used in the early stages of work in order to get feelings about the work being done, how to do it, what is the flow of information and so on.

\subsection{Scenarios}

Scenarios are characteristics of users and their tasks in a specific context. They allow to visualize the user working with the product in order to achieve a specific goal [15]. The goal of using scenarios in the early stages of design is to improve the quality and userfriendliness of the user's requirements presented to the project team. In later stages scenarios can be used during design and evaluation.

\subsection{Card sorting}

Card sorting is a technique that allows designers to see how users link elements of a website or application interface into groups. Each element is saved on a small card (in a typical card sorting session about 30 to 80 cards are allocated). Users, working alone or in pairs, sort the received cards into groups, and then give the groups names. The designer can use this information to better organize the site structure. There is a variation of this method, called Reverse Card Sorting, which provides users with main category names along with cards showing information and features available on the site. The examined persons, 
instead of combining functions into groups, assign them to predefined main categories [21, 26].

\subsection{Interview techniques}

In this method, users (experienced and / or new) are asked by in-depth questions to get subjective opinions about the feelings of using the product. Interviews may take the form of predefined lists (structured) and / or may allow users to freely formulate opinions (unstructured) [1]. The type, detail and objectivity of the collected data depend on both the type of interview and the researcher's experience.

\subsection{Questionnaires (Survey)}

Questionnaires include sets of saved questions asked to large numbers of users. They can be useful in acquiring information, including on how to work and settings for processes and interfaces. First of all, we distinguish between closed questions, in which the respondent chooses from predefined answers and open answers, where he can give any answer. The cantaterers are then processed using statistical methods [22].

\subsection{Parallel design}

Several different project groups prepare parallel versions of the interface concept. The purpose of this is to prepare and evaluate various interfaces before choosing the one that will be directed for further work. Project groups must work independently because the goal is to get as much diversity as possible. Designers are not allowed to discuss projects until they are presented. One of the concepts or a combination of the best features among many presented concepts may be chosen [11]. Although parallel design may seem expensive, because many concepts are created without their implementation, it is in fact an effective way of discovering a wide spectrum of possible project concepts and selecting the optimal design.

\subsection{Paper prototyping}

The method of paper prototypes uses the simplest materials to perform interface simulation based on elements drawn (and / or cut, attached) on paper. Its purpose is to study the requirements (or feelings) of users. After the paper prototype is prepared, a member of the research team sits down in front of the user and plays the role of a computer (namely changes in the interface - content of the monitor) by moving the interface elements in response to the actions taken by the user. The user makes selections and launches interface elements using fingers to indicate (and voice for possible data entry). Users are instructed about required tasks, and during their performance are encouraged to share thoughts, insights and feelings. Members of the research team note observations and obtained comments $[4,18]$. This method is useful when it is easy to simulate the operation of the system and it is not necessary to very accurately reproduce the screen elements.

\subsection{Cognitive walk through}

The step-by-step process (although in Poland too the English name - cognitive walk through) of the tested product or system is used along with collecting the observed reactions of key team members or typical users. One or two team members usually conduct the transition process (subsequent steps in using a product or system) while others comment on their feelings and observations [2].

\subsection{Heuristic evaluation}

Heuristic evaluation is an expert study method that identifies general usability problems that can be expected when using a product. It usually requires at least three system experts in accordance with established guides, rules and lists. The result is noted observations often ordered in accordance with their significance. It is a quick and effective method [3]. 


\subsection{Participatory evaluation}

It is a cost-effective technique for identifying utility problems in prototypes. It consists in encouraging the cooperation of end users and members of project teams in order to identify problems and find solutions. The result is a qualitative information about the difficulties in use when trying to perform tasks and other elements of the interface that cause problems [10].

\subsection{User-based testing of design / interaction}

This method offers a relatively fast and cheap way to evaluate an existing product or prototype by the user.

When testing the system, it focuses on completing the task and getting feedback, in particular on where users are unable to complete tasks or need help in completing them. Particular emphasis is put on testers representing typical users. Detailed test records are not needed. Researchers make records during the interaction of testers performing the imposed tasks and identify the most important problems [25].

In the case of interaction testing, it is suitable for assessing both the high quality of interactive prototypes and Web sites. The surroundings and the tested product should be as close as possible to reality. Researchers in this case also take notes, they can also use audio and / or video recordings. Then, the observations are analyzed and relevant metrics used in the field of usability.

\subsection{Eyetracking}

The eye-tracking method allows the analysis of the perception of websites from the user's perspective (in opposition to, among others, process perspective or service perspective). The history of this research method dates back to the nineteenth century, when the first eyetracking devices were used by psychologists and physiologists. In the thirties of the last century, research devices appeared that can be considered conceptually similar to contemporary ones [5]. Currently, eye-tracking studies are carried out using computer hardware. The advantage of eye-tracking research is the 'natural' way for the respondent to acquire data, as well as the limited conscious control of the respondent over the course of the study itself [9]. In the field of marketing, these studies are used in many areas, including assessment of advertisements, packaging or websites [19].

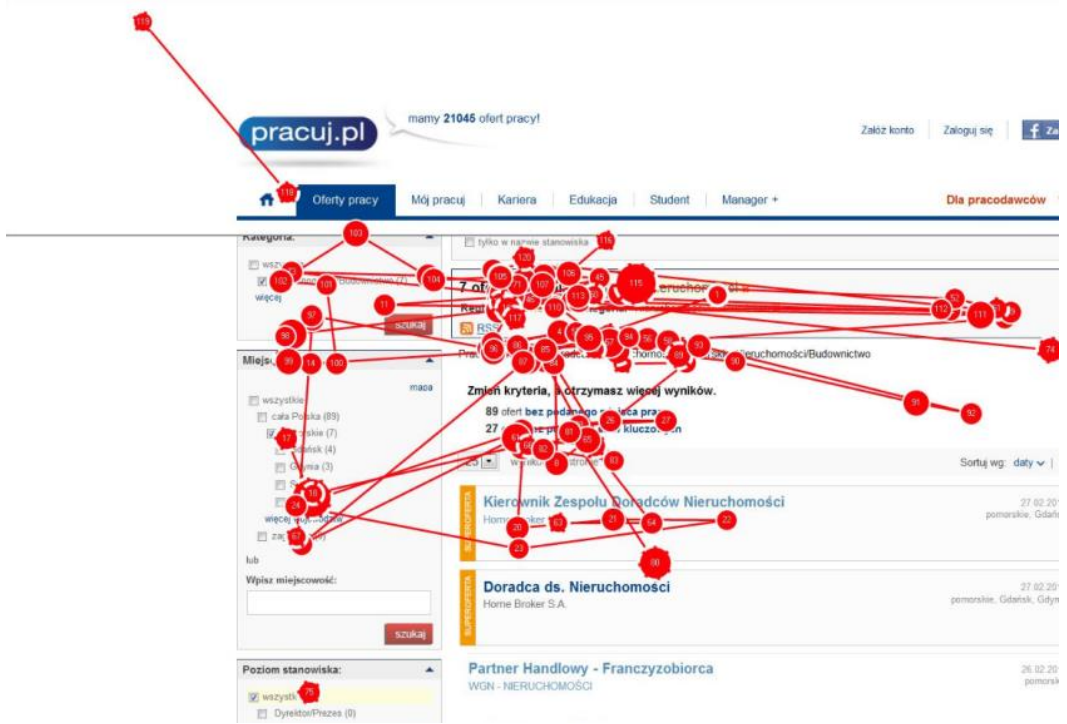

Fig. 3. Sample Gaze-plot of site pracuj.pl. 
Sample test result using eyetracking gaze-plot method is presented on Fig. 3 [19].

Each of the described methods has its own characteristics. This implies that during whole process of preparing, developing and use of interfaces of diagnostic tools, different methods may be used. In particular, one may point three consecutive phases of the preparation process of the diagnostic tool interface design. These are: specification of requirements (which takes place mainly before whole design process starts), concept design and testing and evaluation (usually after tool is designed). The potential use of methods in individual design phases is presented in Tab. 1.

Table 1. Usability techniques possible to use in the diagnostic tools interface design process.

\begin{tabular}{|c|c|c|c|}
\hline & $\begin{array}{l}\text { Requirements } \\
\text { specification }\end{array}$ & $\begin{array}{c}\text { Concept } \\
\text { design }\end{array}$ & $\begin{array}{l}\text { Testing and } \\
\text { evaluation }\end{array}$ \\
\hline 1. Analysis of the context of use & $\mathrm{v}$ & & \\
\hline 2. Task analysis & $\mathrm{v}$ & & \\
\hline 3. Focus groups & $\mathrm{v}$ & & \\
\hline 4. Obsservation & $\mathrm{v}$ & & \\
\hline 5. Request for context (Contextual inquiry & $\mathrm{v}$ & & \\
\hline 6. Scenarios & $\mathrm{v}$ & $\mathrm{v}$ & \\
\hline 7. Card sorting & $\mathrm{v}$ & $\mathrm{v}$ & \\
\hline 8. Interview techniques & $\mathrm{v}$ & $\mathrm{v}$ & \\
\hline 9. Questionnaires (Survey) & $\mathrm{v}$ & & $\mathrm{v}$ \\
\hline 10. Parallel design & & $\mathrm{v}$ & \\
\hline 11. Paper prototyping & & $\mathrm{v}$ & \\
\hline 12. Cognitive walk through & & $\mathrm{v}$ & $\mathrm{v}$ \\
\hline 13. Heuristic evaluation & & $\mathrm{v}$ & $\mathrm{v}$ \\
\hline 14. Participatory evaluation & & $\mathrm{v}$ & $\mathrm{v}$ \\
\hline 15. User-based testing of design / interaction & & & $\mathrm{v}$ \\
\hline 16. Eyetracking & & & $\mathrm{v}$ \\
\hline
\end{tabular}

\section{CONCLUSIONS}

The development of diagnostic tools has caused a rapid increase in the amount of information generated and presented, necessitating the use of computer displays as an interface to data presentation and the use of modern diagnostic tools. At the same time, the increased complexity of modern devices has caused an avalanche increase in the demand for the use of diagnostic tools and the necessity of designing their interfaces so that they are simple and user-friendly. Usability techniques presented in this paper may be used for improving quality of modern diagnostic tools in order to make them more user-friendly.

\section{References}


1. J. Anderson, F. Fleek, K. Garrity, F. Drake, Integrating Usability Techniques into Software Development, January/February 2001, IEEE SOFTWARE (2001)

2. M. H. Blackmon, P. G. Polson, M. Kitajima, C. Lewis, Cognitive walkthrough for the web, CHI '02 Proceedings of the SIGCHI Conference on Human Factors in Computing Systems, ACM (2002)

3. J. St. B. T. Evans, The heuristic-analytic theory of reasoning: Extension and evaluation, Psychonomic Bulletin \& Review, June 2006, Vol. 13, Iss. 3 (2006)

4. Eileen G. Abelse, Marilyn Domas White, Karla Hahn, A user-based design process for Web sites, Internet Research, Vol. 8 Iss. 1 (1998)

5. Gofman A., Moskowitz H.R., Fyrbjork J., Moskowitz D., Mets M. (2009), Extending Rule Developing Experimentation to Perception of Food Packages with Eye Tracking, Open Food Science Journal; Vol. 3 (2009)

6. Kossecki, P.; Wachowicz, J. Świerczyńska-Kaczor, U.;. Possible Stress Factors for Elderly Users in Online Human Resources Services, in: Psychology\&Health vol. 28, Taylor\&Francis (2012)

7. Ludwiszewski, B.; Redlarski, K.; Wachowicz J.. Możliwości zastosowania metody Kansei Engineering w projektowaniu usług on-line dla osób zagrożonych wykluczeniem cyfrowym, in : Interfejs użytkownika. Kansei w praktyce, eds. Sikorski M., Marasek K., pp. 88-96, Warszawa, PJWSTK (2011)

8. M. Maguire, Context of Use Within Usability Activities, Int. J. Human-Computer Studies (2001)

9. Meißner M., Decker R. (2010), Eye-Tracking Information Processing In Choice-Based Conjoint Analysis, International Journal of Market Research; Vol. 52 Issue 5 (2010)

10. M. J. Muller, L. Matheson, C. Page, R. Gallup, Methods \& tools: participatory heuristic evaluation, interactions, Interactions, Vol. 5 Iss. 5, Sept./Oct. 1998 ACM (1998)

11. J. Nielsen ; J.M. Faber, Improving system usability through parallel design, Computer, Vol. 29 Iss. 2 • Feb. 1996, IEEE (1996)

12. Task Analysis, usability.gov, https://www.usability.gov/how-to-andtools/methods/task-analysis.html, accessed 2018-05-03

13. J. Nielsen, The use and misuse of focus groups, IEEE Software, Vol.: 14 Iss.: 1 , IEEE

14. R3UEMs: Review, Report and Refine Usability Evaluation Methods: The 3rd COST294-MAUSE International Workshop, 5th March 2007, Athens, Greece, eds. Scapin D., Law. E (2007)

15. T. Rafla, P. N. Robillard, M. Desmarais, Investigating the impact of usability on software architecture through scenarios: a case study on web systems, http://rafla.tripod.com/TR-Article_Final.pdf, accessed 2018-05-12

16. Redlarski, K.; Kossecki, P.; Ludwiszewski, B.; Świerczyńska-Kaczor, U.; Wachowicz, J.. Czynniki wpływające na efektywność korzystania z multimedialnych serwisów internetowych przez osoby starsze, in: Edukacja dla bezpieczeństwa, pp. 59-70 (2011)

17. Redlarski, K.; Wachowicz, J.; Ludwiszewski B.. Online services for the elderly towards a better quality of life: What encourages, what discourages? In: Psychology \& Health 28, (2012)

18. S. Reinhard, M. Tscheligi, V. Giller. "Paper prototyping - what is it good for?: a comparison of paper- and computer-based low-fidelity prototyping." CHI Extended Abstracts (2003).. 
19. Świerczyńska-Kaczor, U.; Wachowicz, J.. Ocena dostosowania internetowych serwisów rekrutacyjnych do potrzeb osób starszych - metoda eye-tracking, in : Rozwój potencjału społecznego organizacji - wyzwania w XXI wieku, eds. Klincewicz K., Grzywacz W., pp. 215-230, Warsaw University (2012)

20. S. M. Thompson, Remote observation strategies for usability testing, Information Technology and Libraries; Chicago Vol. 22, Iss. 1, (2003):

21. Wachowicz J. Card Sorting,, in: R3UEMs: Review, Report and Refine Usability Evaluation Methods: The 3rd COST294-MAUSE International Workshop, 5th March 2007, Athens, Greece, eds. Scapin D., Law. E., (2007)

22. Wachowicz J. Data Gathering Methods: Review - Questionnaire, in: R3UEMs: Review, Report and Refine Usability Evaluation Methods: The 3rd COST294-MAUSE International Workshop, 5th March 2007, Athens, Greece, eds. Scapin D., Law. E., (2007)

23. Wachowicz, J.. Information Society in Poland - Similarities and Differences in the Perception of ICT Between Generations, in: Information Systems: Development, Research, Applications, Education. 9th SISGSAND/PLAIS EuroSymposium 2016 Gdańsk, Poland, ed.: Wrycza S., LNBIP 264, Lecture Notes in Business Information Processing, Springer (2016)

24. Wachowicz, J.; Ludwiszewski, B.; Redlarski, K. (2012). Factors Disturbing Internet Usage in Opinion of Elderly Users, in: Managerial Challenges of the Contemporary Society, Vol. 4, 2012, Risoprint, Cluj-Napoca, Romania, (2012)

25. L. White, H. Almezen, N. Alzeidi, User-based testing of GUI sequences and their interactions,. ISSRE 2001. Proceedings.of 12th International Symposium on Software Reliability Engineering, 2001, IEEE xPlore (2001)

26. J. R. Wood, L. E. Wood, Card Sorting: Current Practices and Beyond, Journal of Usability Studies, Vol. 4, Issue 1, November 2008, (2008) 